\title{
A CONSTRUÇÃO DA ARGUMENTAÇÃO NO RESUMO ACADÊMICO A PARTIR DA UTILIZAÇÃO DOS OPERADORES DE CONTRAPOSIÇÃO
}

\author{
Marcos Antônio da Silva ${ }^{i}$ \\ Luiz Henrique Santos de Andrade ${ }^{\text {ii }}$
}

Resumo: Este estudo analisa a polifonia de enunciadores, bem como os operadores argumentativos de contraposição, em resumos acadêmicos que fazem parte de um projeto "guarda-chuva" maior. Para tal empreendimento, lançamos mão da Teoria da Argumentação na Língua proposta por Oswald Ducrot $(1987,1988)$ e Anscombre e Ducrot $(1983,1994)$. A metodologia empregada é de natureza descritiva e qualitativa, tendo em vista que estamos atentos ao funcionamento desses operadores tanto como elementos coesivos quanto pelo fato de serem utilizados como uma estratégia argumentativa, orientando os enunciados para determinadas conclusões. A análise realizada no corpus, constituído de cinco resumos acadêmicos, constatou que se trata de um gênero discursivo que apresenta como principal estratégia argumentativa a polifonia de enunciadores, em que os operadores de contraposição analisados não funcionam apenas como elementos de ligação de palavras e orações, mas também ativam pontos de vista diferentes, corroborando para o leitor perceber 0 posicionamento do locutor responsável pelo texto.

Palavras-chave: Argumentação. Operadores argumentativos. Polifonia de enunciadores. Resumo acadêmico.

\begin{abstract}
This paper analyzes the polyphony of enunciators as well as the argumentative operators of contraposition in academic abstracts which are part of a larger umbrella project. For this research, we use the Theory of Argumentation Within Language proposed by Oswald Ducrot $(1987,1988)$ and Anscombre and Ducrot $(1983,1994)$. The methodology is descriptive and qualitative in nature, considering that we are attentive to the working of these operators as cohesive elements as well as the fact that they are used as an argumentative strategy, guiding the statements to certain conclusions. Through the analysis of the corpus, which is composed by five academic abstracts, we found that this discursive genre presents as the main argumentative strategy the polyphony of enunciators, in which the contraposition operators analyzed do not only function as elements of linking words and statements, but they activate different points of view, corroborating for the reader to perceive the positioning of the responsible locutor through the text.
\end{abstract}

Keywords: Argumentation. Argumentative operators. Polyphony of enunciators. Academic abstract genre.

\footnotetext{
' Doutor em Linguística pela Universidade Federal da Paraíba (UFPB). Docente do Instituto Federal de Alagoas (IFAL), Brasil. E-mail:marco_sil2@hotmail.com.

ii Doutorando em Linguística pela Universidade Federal da Paraíba (UFPB). Docente da Universidade Estadual da Paraíba (UEPB), Brasil. E-mail: luizao_andrade2008@hotmail.com.
} 
EID\&A - Revista Eletrônica de Estudos Integrados em Discurso e Argumentação, Ilhéus, n. 14, jul/dez.2017.

\section{Introdução}

O exercício da língua/gem, quer seja na modalidade oral quer seja na escrita, está presente nas pessoas desde a sua mais tenra idade até a velhice, tendo em vista que, todos os dias, os indivíduos de uma sociedade são levados a expor seus pensamentos, seus desejos, suas intenções e suas opiniões, diante dos mais variados temas e assuntos. Assim, a língua/gem constitui muito mais do que um meio de comunicação entre os membros de uma comunidade ou uma forma de descrever a realidade do mundo, mas um processo por meio do qual esses membros podem interagir uns com os outros e sobre os outros.

Considerando, portanto, o uso contínuo da linguagem e os postulados apresentados por Ducrot (1988) e Anscombre e Ducrot (1994), na Teoria da Argumentação na Língua ${ }^{1}$, em que se afirma que a língua é argumentativa por natureza e que em sua própria estrutura há elementos que orientam os enunciados para determinadas conclusões e possibilidades de continuação, objetivamos apresentar uma análise linguístico-discursiva dos operadores de contraposição, a partir da apreciação de cinco resumos acadêmicos.

De forma mais ampla, é pertinente dizer que nossos olhares incidirão para o fato de que, quando da produção de um resumo acadêmico, texto percebido e descrito como gênero “objetivo", o locutor responsável pelo texto deixa revelar marcas de sua subjetividade e põe em cena outros pontos de vista. Assim sendo, podemos afirmar que os operadores de contraposição constituem uma das formas de construir a argumentatividade almejada pelo locutor do texto, em relação ao modo como o texto produzido requer ser apreendido.

O presente artigo segue a seguinte estrutura organizacional: inicialmente, apresentamos uma breve discussão sobre a Teoria da Argumentação na Língua e, ainda, sobre a questão da Teoria da Polifonia. Em um segundo momento, expomos as questões que envolvem os operadores argumentativos e discutimos a relação entre os operadores de contraposição e a existência de um arrolamento direto com a presença da polifonia nos resumos, isto é, a presença de outras vozes no interior do mesmo enunciado/texto. Em seguida, apresentamos as análises de cinco resumos

\footnotetext{
${ }^{1}$ A Teoria da Argumentação na Língua é postulada a partir da parceria entre Anscombre e Ducrot $(1983,1994)$. As obras datadas de 1987 e 1988, mesmo estando inseridas no contexto de pesquisa e desenvolvimento da supracitada teoria, são de autoria apenas de Ducrot.
} 
EID\&A - Revista Eletrônica de Estudos Integrados em Discurso e Argumentação, Ilhéus, n. 14, jul/dez.2017.

acadêmicos. Pertencem ainda a esse terceiro momento, a exposição da metodologia utilizada em nossas análises, a identificação e a descrição da utilização dos operadores de contraposição no corpus, além da discussão sobre os efeitos de sentido possibilitados por tais estruturas. Por último, com o objetivo de dar um caráter conclusivo ao nosso trabalho, apresentamos as considerações finais pertinentes à relação estabelecida entre as análises empreendidas e o apanhado teórico em que nos baseamos.

\section{A Teoria da Argumentação na Língua: algumas palavras necessárias}

Apresentada ao campo linguístico a partir da obra L'argumentation dans la langue, originalmente publicada em 1983, a Teoria da Argumentação na Língua proposta por Jean-Claude Anscombre e Oswald Ducrot se caracteriza, primordialmente, por ser uma teoria não-referencialista, visto que para esses autores o significado não tem qualquer relação com seu referente no mundo, mas apenas na relação entre os enunciados. Assim sendo, ao produzir um enunciado e ao apresentá-lo a seu interlocutor, o locutor está dando a conhecer o seu ponto de vista sobre o mundo.

A Teoria da Argumentação na Língua postulada por Anscombre e Ducrot $(1883,1994)$, para quem a argumentação está inscrita na língua e à qual nos filiamos, opõe-se à concepção tradicional de sentido de um enunciado. A perspectiva tradicional destaca a existência de três indicações de sentido, a saber: a) objetivas: que representam a realidade e correspondem ao aspecto denotativo; b) subjetivas: que indicam a atitude do locutor frente à realidade e apresentam um aspecto de conotação; e c) intersubjetivas: que se referem às relações entre o locutor e os seus possíveis interlocutores.

Essas três indicações podem ser descritas da seguinte forma, a partir da observação do enunciado abaixo:

Exemplo 01: Emmanuel é inteligente!

Conforme Ducrot (1988) detalha, o aspecto de sentido objetivo está relacionado com a descrição de Emmanuel; o aspecto subjetivo tem relação com o fato de o locutor (produtor do texto) ter alguma espécie de admiração pela inteligência de Emmanuel e, por fim, o aspecto intersubjetivo tem relação direta com o objeto do locutor ao apresentar tal enunciado, em função do que almeja do ouvinte/interlocutor. Assim, se “Emmanuel é inteligente!", característica esta que é levada em conta pelo locutor do enunciado, o seu 
EID\&A - Revista Eletrônica de Estudos Integrados em Discurso e Argumentação, Ilhéus, n. 14, jul/dez.2017.

interlocutor pode "confiar e esperar bons resultados daquilo que for reservado a Emmanuel".

Ducrot (1988), então, defende que nas próprias indicações objetivas, mesmo com a essência referencial ou descritiva, já existe uma carga de argumentatividade, pois a própria descrição da realidade ou referenciação se dá por meio de escolhas dentre as palavras disponíveis na língua. Assim, a atitude do locutor influi no modo como descreve essa realidade e procura atrair a atenção do interlocutor para o que está sendo dito. O posicionamento de Ducrot (1988) é, portanto, o de criticar a separação entre as três indicações de sentido.

Assim, confirmando esse posicionamento, podemos observar que o adjetivo "inteligente", imputado a Emmanuel, não apenas o caracteriza, mas, em relação ao ouvinte, funciona de forma argumentativa, em razão da orientação argumentativa que dá ao enunciado, que resultará na aceitação ou não, pelo outro, do conteúdo proposicional apresentado.

A partir dessa nova perspectiva teórica, as três indicações de sentido foram reorganizadas e concluiu-se que não há neutralidade ao se representar a realidade, de modo que os aspectos "objetivos" passam a não mais existir. Ducrot (1988) unifica, em seguida, os aspectos subjetivos e intersubjetivos, denominando-os valor argumentativo dos enunciados, o que corresponde à orientação dada pela palavra ao discurso e que determina as possibilidades ou impossibilidades de continuação determinadas por seu uso. Os operadores argumentativos são, como veremos, elementos que orientam, ou não, os discursos para determinadas conclusões.

De antemão, é relevante mencionar que a Teoria da Argumentação na Língua é constituída por quatro etapas, a saber: Descritivismo Radical, Descritivismo Pressuposicional, A argumentação como constituinte da significação e a Argumentatividade Radical. No primeiro momento, de forma bem sintética, é possível dizer que língua e argumentação eram percebidas de forma separadas, já que a base da teoria é de inspiração estruturalista. Para Ducrot (1988) e Anscombre e Ducrot (1994), portanto, nesse primeiro momento, a estrutura linguística não guardaria qualquer relação com a argumentação presente no enunciado.

Na segunda etapa, Descritivismo Pressuposicional, de forma discreta, a argumentação é sugerida a partir da relação entre enunciados elaborados com elementos como "pouco" e "um pouco". Os autores chegam, inclusive, a 
EID\&A - Revista Eletrônica de Estudos Integrados em Discurso e Argumentação, Ilhéus, n. 14, jul/dez.2017.

afirmar que não há muita diferença entre essas duas primeiras etapas, tendo em vista que a segunda é, na verdade, um ajuste do posicionamento apresentado na primeira. Assim, a orientação argumentativa estaria presente na percepção que o leitor teria a partir dos conteúdos proposicionais presentes nos enunciados elaborados com "pouco" ou "um pouco".

Logo, entre os enunciados do exemplo abaixo:

Exemplo 02: João dormiu pouco: logo, não pode dirigir e João dormiu um pouco: logo pode dirigir,

haveria uma orientação argumentativa, possibilitada pelas expressões "pouco" e "um pouco" que orientaria o leitor/ouvinte para a produção de conclusões diferentes.

De posse de uma gama maior de exemplos de enunciados com operadores argumentativos, Ducrot (1988), na terceira etapa, A argumentação como constituinte da significação, ressalta que uma possível ideia de quantidade entre "pouco" e "um pouco" deve ser abandonada, tendo em vista que, nos dois casos do exemplo apresentado, a conclusão seria a de que "João havia dormido". O fato que residia na diferença entre os operadores "pouco" e "um pouco" reside, agora, na orientação argumentativa e, sendo assim, a frase pode comportar diversos morfemas, expressões ou termos que, além de seu conteúdo informativo, servem para dar uma orientação argumentativa ao enunciado, conduzindo o destinatário para uma ou outra direção.

Ainda que a argumentação na língua já tenha sido percebida na terceira etapa, Ducrot (1988) apresenta uma quarta, A Argumentatividade Radical, em que afirma que, dentro da própria estrutura da língua, há elementos que funcionam como a ossatura interna dos enunciados. Logo, para esse autor, há expressões na língua que por si mesmas têm um valor argumentativo. A argumentação, dessa forma, estaria inscrita na língua. Conforme já antecipamos, os operadores argumentativos constituem um dos grupos de palavras que tem por função orientar os enunciados para determinadas conclusões.

Além dessas noções preliminares, é importante compreender outro conceito inserido por Ducrot (1987) nos estudos linguísticos, como é o caso do termo polifonia, que será mais bem detalhado no próximo tópico. 
EID\&A - Revista Eletrônica de Estudos Integrados em Discurso e Argumentação, Ilhéus, n. 14, jul/dez.2017.

\subsection{A Noção de Polifonia nos Estudos Linguísticos}

Assim como rompeu com a tradição, no que diz respeito às indicações de sentido de enunciado, Ducrot (1988) quebra a tradicional crença na unicidade do sujeito, mostrando que em um mesmo enunciado o locutor põe diferentes sujeitos em cena.

O termo polifonia, que significa 'várias vozes', serve, na Teoria Polifônica da Enunciação, para designar os locutores e enunciadores presentes no discurso. Usado por Ducrot (1987) nos estudos linguísticos como empréstimo, o termo foi utilizado, inicialmente, por Bakhtin (1981), inspirado na composição musical em que várias vozes são superpostas para caracterizar, em seus estudos sobre literatura, o romance de Dostoiévski, no qual a voz do personagem é tão plena como a voz do autor, não havendo subordinação. No entanto, é preciso destacar que, enquanto na perspectiva do universo literário o termo "polifonia" expressa uma noção que relaciona fatores históricos, culturais e ideológicos, ou seja, fatores externos à língua, na linguística, o termo tem relação com os pontos de vista que são apresentados, por um locutor, em um determinado enunciado, estritamente a partir de elementos linguísticos.

Para a efetiva compreensão da teoria polifônica, é imprescindível a compreensão de alguns conceitos, tais como: sujeito empírico, locutor e enunciador. O sujeito empírico (SE), segundo Ducrot (1988), é aquele que produz o enunciado. Já o locutor $(L)$ é aquele a quem é atribuída a responsabilidade pelo enunciado; há marcas linguísticas que indicam a possibilidade de identificação do locutor (L), a saber: pronomes pessoais (eu, me, mim) ou, em alguns casos, marcas espaciais ou temporais como aqui, agora, por exemplo. O enunciador (E) é quem traz os diferentes pontos de vista que se apresentam no enunciado, ou seja, as perspectivas abstratas.

Outra distinção importante na teoria polifônica da enunciação é entre a polifonia de enunciadores e a polifonia de locutores. De forma sintética, podemos explicar que a polifonia de enunciadores ocorre quando o locutor apresenta perspectivas diferentes no enunciado. De acordo com Ducrot (1988), esse tipo pode ocorrer em situações de humor, ironia, pressuposição, negação e enunciados com o mas. Ressaltamos que, no interior da Teoria da Argumentação na Língua, mas é elemento ativador de polifonia por excelência, como é o caso do enunciado: "O tempo está muito agradável para uma caminhada na praia, mas estou com dor de cabeça”. A presença das 
EID\&A - Revista Eletrônica de Estudos Integrados em Discurso e Argumentação, Ilhéus, n. 14, jul/dez.2017.

diversas vozes estaria, nesse enunciado, marcada pela existência de um primeiro enunciador que diz "O tempo está muito agradável para uma caminhada na praia", de um segundo que conclui "Vamos à praia", de um terceiro que afirma "estou com dor de cabeça" e de um quarto, que se coloca como conclusão do terceiro, apresentando a resolução "Não vamos à praia". Logo, temos em um único enunciado a presença dos quatro pontos de vista, o que fortalece o intuito de Ducrot (1988) com a desmistificação da unicidade do sujeito falante.

Consequentemente, os enunciadores são compreendidos por Ducrot (1987) como:

[...] seres que são considerados como se expressando através da enunciação, sem que para tanto se lhe atribuam palavras precisas; se eles "falam" é somente no sentido em que a enunciação é vista como expressando o seu ponto de vista, sua posição, sua atitude, mas não, no sentido material do termo, suas palavras.

Ainda segundo o referido teórico, o locutor pode se posicionar em relação aos enunciadores de algumas formas: identificando-se, aprovando um ponto de vista ou opondo-se a ele. Tais comportamentos podem ser explicados da seguinte forma: o locutor se identifica com um dos enunciadores, por exemplo, nos casos de asserção, quando o locutor apresenta um ponto de vista e assume esse ponto de vista. Se o locutor apresenta o ponto de vista segundo o qual "Pedro vem", ele se identifica com esse ponto de vista à medida que tem como objetivo impor o ponto de vista desse enunciador, ou seja, o locutor faz admitir a vinda de Pedro.

O caso de aprovação (1988, p. 66) ocorre quando "[...] o locutor indica que está de acordo com esse enunciado [...]", ainda que para isso não queira fazer admitir o ponto de vista apresentado pelo enunciador. $\mathrm{O}$ autor informa que exemplo de casos de aprovação podem ser encontrados na pressuposição, quando se tem, por exemplo: João deixou de beber cachaça.

Ainda de acordo com Ducrot (1987, p. 193), é o locutor, enquanto responsável pelo enunciado como um todo, quem "[...] dá existência, através deste, a enunciadores de quem ele organiza os pontos de vista e as atitudes". Além disso, o autor completa seu pensamento, afirmando que a posição do locutor pode se manifestar, porque há uma assimilação entre o locutor e, pelo menos, um dos enunciadores - o que faz com que esse locutor tome um enunciador como representante, implicando, dessa forma, a atualização desse enunciador -, ou simplesmente porque o locutor desejou fazer aparecer um 
EID\&A - Revista Eletrônica de Estudos Integrados em Discurso e Argumentação, Ilhéus, n. 14, jul/dez.2017.

dos enunciadores, sem que para isso o locutor se assimile a um determinado enunciador.

Quanto à polifonia de locutores, para Ducrot (1987, p. 185), ela pode ser encontrada no discurso relatado em estilo direto, como no seguinte exemplo:

Exemplo 03: João me disse: eu virei.

Há, no enunciado anterior, dois locutores, a saber: o locutor L1, que é responsável por todo o enunciado "João me disse: eu virei." e o locutor L2, responsável pelo segmento "eu virei". Assim, ao observar que há no enunciado a presença dos dois pronomes "me" e "eu", e que tais pronomes são pertencentes a locutores distintos, Ducrot (1987) mostra como no mesmo enunciado podem existir várias vozes em cena.

A ocorrência de polifonia de locutores também pode se dar pelo discurso relatado, pelas aspas, uma das formas de argumentação por autoridade, e por outras formas que não serão apresentadas neste trabalho, por motivo de espaço e opção metodológica.

\section{Os Operadores de Contraposição e a Presença da Polifonia de Enunciadores}

Apoiada nas pesquisas desenvolvidas pelos estudiosos da Teoria da Argumentação na Língua, Koch (2004) apresenta, ao dedicar-se ao estudo dos operadores argumentativos, expressão cunhada por Anscombre e Ducrot (1994) no interior da Semântica Argumentativa, os dois tipos de operadores: os do tipo lógico e os do tipo discursivos ou argumentativos.

Os operadores do tipo lógico, segundo Koch (2004, p. 120), são aqueles utilizados com a função de ligar "[...] apenas proposições dentro do mesmo enunciado, transformando predicados simples em complexos e dando origem a frases ligadas [...]". Nesse caso, referem-se aos operadores presentes nas orações subordinadas. Esse tipo de operador é constituído pelas proposições compostas, como as copulativas, disjuntivas, condicionais, causais, relativas e descritivas. Como exemplo desse operador, a autora apresenta:

Exemplo 04: Se a alma é espiritual, ela é imortal.

No exemplo 04, o operador "se" faz-se presente em uma proposição do tipo condicional, que "[...] são proposições formadas de duas partes ligadas pela conjunção se, em que a primeira, que encerra a condição, constitui o antecedente, e a segunda, o consequente", conforme Koch (2004, p. 124). 
Os operadores do tipo discursivo ou argumentativo, ainda conforme essa mesma autora (2004, p. 120), são aqueles que “[...] aparecem não só entre as orações de um mesmo período, mas também encadeando orações de períodos diferentes ou encadeando parágrafos diferentes".

Vejamos:

Exemplo 05: Conversei ontem com seu pai, tanto que ele estava gripado.

Um dos locutores já havia afirmado que "seu pai estava gripado". Assim, um segundo locutor (L2), com o propósito de verificar/comprovar, afirma e, possivelmente, retoma o enunciado dito anteriormente pelo locutor $L 1$.

Vejamos a representação com a retomada desse exemplo:

L1 - Meu pai está gripado.

L2- Conversei com seu pai, tanto isso é verdade que pude verificar que ele estava gripado.

Assim, segundo Koch (2004, p. 130), "[...] a segunda proposição não se relaciona sintaticamente com a primeira, mas sim com o modo de afirmação, estabelecendo um elo com as condições subjetivas da enunciação" (grifos da autora). Adotar, porém, essa proposta de classificar os operadores em tipos lógicos ou discursivos "[...] exigiria, evidentemente, uma reclassificação das conjunções usualmente consideradas como coordenativas e como subordinativas pelas gramáticas tradicionais", afirma Koch (2004, p. 120).

Retomando o que afirma Koch (1999, p. 17), é pertinente dizer que os operadores têm como função relacionar semanticamente elementos no interior do texto, essenciais para a sua interpretação. Ela ainda afirma que "[...] a coesão, por estabelecer relações de sentido, diz respeito ao conjunto de recursos semânticos por meio dos quais uma sentença se liga com a que veio antes, aos recursos semânticos mobilizados com o propósito de criar textos". O funcionamento dos operadores argumentativos, quando da produção textual, pode ser percebido, portanto, como um recurso coesivo.

3. Os operadores de contraposição como marcas argumentativas nos resumos acadêmicos: momento de análises

Apresentamos, a seguir, as análises dos cinco resumos acadêmicos. Os textos trazidos para este artigo fazem parte de uma pesquisa maior e, com a intenção de não identificarmos sujeitos, informações como título e nome dos autores foram suprimidas. 
EID\&A - Revista Eletrônica de Estudos Integrados em Discurso e Argumentação, Ilhéus, n. 14, jul/dez.2017.

A pesquisa é de natureza descritivo-qualitativa, uma vez que nosso objetivo é o descrever e analisar o funcionamento dos operadores de contraposição no gênero resumo acadêmico, gênero este concebido por alguns manuais didáticos como um texto de caráter objetivo e, de certa forma, desprovido de qualquer argumentatividade.

A coleta dos resumos ocorreu durante os anos de 2011 e 2012 em diferentes suportes, a saber: revistas digitais e impressas, anais impressos e eletrônicos de congressos nacionais e internacionais. O processo de análise dos resumos acadêmicos obedeceu à seguinte ordem: leitura dos resumos, identificação e descrição dos operadores de contraposição e análise dos efeitos de sentido que tais operadores conferiram aos textos, observando, evidentemente, a polifonia de enunciadores presente no texto bem como $o$ posicionamento do locutor.

\begin{abstract}
Resumo 01:
Mapas Conceituais são ferramentas gráficas para organização e representação de conhecimento. Nesta década, houve um crescente interesse pela construção de mapas conceituais a partir de fontes de dados como forma de superar as dificuldades de construção a partir do "zero". Identificamos, contudo, a ausência de referências consistentes que permitissem a caracterização desta área de pesquisa. Portanto, com o intuito de preencher esta lacuna, propomos uma série de características para análise das abordagens de construção (semi) automática de mapas conceituais. Este artigo é parte integrante de uma pesquisa que investiga o uso de mapas conceituais em ambientes virtuais de aprendizagem.
\end{abstract}

Com base na leitura do resumo 01, percebemos a existência do operador de contraposição contudo. A partir da presença de tal operador, é possível identificarmos pelo menos quatro enunciadores, ou pontos de vista, colocados em cena pelo locutor responsável pelo texto, como elementos constituintes para a construção da argumentação do locutor, tais como:

E1: Nesta década, houve um crescente interesse pela construção de mapas conceituais a partir de fontes de dados como forma de superar as dificuldades de construção a partir do "zero".

E2: Há investigações que dão conta da análise desse fenômeno.

E3: Identificamos, contudo, a ausência de referências consistentes que permitissem a caracterização desta área de pesquisa.

E4: Não há investigações que dão conta da análise desse fenômeno.

É pertinente pontuar, ainda, que E2 e E4 são totalmente opostos, ou seja, o operador de contraposição "contudo" funciona como operador argumentativo que irá orientar, a partir da apresentação de E1 e E3, a 
EID\&A - Revista Eletrônica de Estudos Integrados em Discurso e Argumentação, Ilhéus, n. 14, jul/dez.2017.

produção de conclusões que são contrárias. O locutor do texto, responsável pela produção do enunciado como um todo, diante desses quatro pontos de vista postos por ele em cena, assume o seguinte posicionamento: rechaça E2, identifica-se com E3 e E4 e aprova E1.

É relevante observar que a ocorrência do operador de contraposição "contudo" decorre, conforme o locutor do texto, do fato da não existência de investigações que deem conta da construção de mapas conceituais. Assim, para tal locutor, sua pesquisa, apresentada no resumo, tem relevância. Esse posicionamento do locutor, enquanto justificativa de sua pesquisa, é apresentado, na continuidade do texto, por "portanto", operador que introduz conclusão relativa aos argumentos expostos anteriormente, a saber, algo como: "não há investigações, portanto irei apresentar referências que ajudem essa área".

Argumentativamente falando, o locutor fez uso de dois operadores para não apenas apresentar pontos de vista diferentes, mas para, de forma intencional, mostrar a importância que sua investigação tem na área de pesquisa por ele referida. Ressaltamos que, ainda que o segundo operador, 0 "portanto", não faça parte do grupo dos operadores de contraposição, considerando o gênero aqui em análise, não poderia ser deixado à margem dos nossos olhares, tendo em vista a sua função, o efeito de sentido que ele causa na completude do texto e a contribuição para a construção da argumentação no todo do texto.

\footnotetext{
Resumo 02:

Neste trabalho, apresentamos um novo sistema de apoio ao ensino/aprendizagem via Web, o iComb. Também apresentamos alguns experimentos didáticos com a atual proposta do iComb. Este sistema é baseado na experiência do Combien?, desenvolvido pela Université Pierre et Marie Curie, que tem bons recursos para auxílio à resolução de exercícios ligados a análise combinatória, mas apresenta limitações quanto à incorporação de novos exercícios e principalmente apresenta restrições para seu uso via Web. Uma inovação advinda deste projeto é que o iComb pode ser integrado a sistemas gerenciadores de cursos, como o Moodle. Além disso, o iComb pode ser incorporado a páginas pessoais, redes sociais e blogs, na forma de um "widget".
}

No resumo 02, observamos a ocorrência do operador de contraposição "mas", linguisticamente apresentado como operador argumentativo por excelência. Tal elemento, assim como nos demais casos, ativa a polifonia de enunciadores, isto é, a presença de quatro enunciadores, como podemos constatar no esquema polifônico abaixo: 
EID\&A - Revista Eletrônica de Estudos Integrados em Discurso e Argumentação, Ilhéus, n. 14, jul/dez.2017.

E1: Este sistema é baseado na experiência do Combien?, desenvolvido pela Université Pierre et Marie Curie, que tem bons recursos para auxílio à resolução de exercícios ligados a análise combinatória

E2: o sistema é adaptável ao ambiente moodle.

E3: mas apresenta limitações quanto à incorporação de novos exercícios e principalmente apresenta restrições para seu uso via Web

E4: o sistema não é totalmente adaptável ao ambiente moodle.

No caso do resumo 02, percebemos que o ponto de vista de E1 é que o sistema "Combien?" funcionará como uma ferramenta que auxiliará o trabalho com análise combinatória. O fato de ajudar, portanto, não é rechaçado totalmente em E2, visto que, mesmo apresentando limitações quanto ao seu uso e objetivo, ainda assim, o sistema ajudará, de alguma maneira, como se depreende em E4.

O locutor, dessa forma, responsável pelo enunciado como um todo, adota o seguinte posicionamento frente aos enunciadores: rechaça parcialmente E2, pois o fato de o "sistema não ser totalmente adaptável à internet" (E4), não indica que ele não seja "seja adaptável” de alguma forma. Portanto, não há um rechaço total, mas de forma parcial.

A identificação com E3 e E4 ocorre quando esses enunciadores são apresentados e assumidos pelo locutor. Da mesma forma, a aprovação de E1 ocorre quando o locutor dá sua concordância em relação ao ponto de vista de que o sistema "tem bons recursos para auxílio à resolução de exercícios ligados à análise combinatória”.

Assim como nos dois resumos anteriores, percebemos que o operador presente no texto é utilizado objetivando um efeito de sentido que dê ainda mais força argumentativa ao conteúdo apresentado. Prova disso é o elemento "além disso", que o locutor traz à tona no último período do seu resumo. Considerando que o operador "além disso" soma argumentos a favor de uma mesma conclusão, tal ocorrência só reforça a nossa ideia de que a argumentação vem sendo construída ao longo de todo o texto e é reforçada, por meio da presença dos vários pontos de vista, com os operadores de contraposição.

Resumo 03:

Este trabalho investigativo consiste numa análise quanti-qualitativa sobre fóruns de discussão em comunidades de aprendizagem. As leituras de Losada (1999), bem como Araújo e Lucena (2005) instigaram-nos a procurar uma relação entre o nível de cordialidade entre os grupos e a construção de conhecimento em suas discussões. Com base na teoria sócio-histórica temos que o desenvolvimento 
EID\&A - Revista Eletrônica de Estudos Integrados em Discurso e Argumentação, Ilhéus, n. 14, jul/dez.2017.

cognitivo dos sujeitos se dá a partir das suas atividades inter-relacionais em seus grupos de convívio. Contudo, a simples interação não é suficiente para que o sujeito se aproprie de novas habilidades cognitivas. Nossos fóruns mostraram que interações com alta taxa de positividade nem sempre resultam numa construção coletiva de conhecimento.

Na ocorrência do operador "contudo", no resumo 03, observamos que o argumento de que "o desenvolvimento cognitivo do sujeito se dá por meio de atividades interacionais dentro dos grupos de convívio" permite que o interlocutor conclua que "a interação é suficiente para esse desenvolvimento cognitivo dos sujeitos".

Mas, com a introdução do operador "contudo" no início da outra proposição, um novo argumento é inserido: "Contudo, a simples interação não é suficiente para que o sujeito se aproprie de novas habilidades cognitivas". Assim, considerando a inserção de "contudo", o ouvinte deverá elaborar outra conclusão, a de que "apenas a interação não é suficiente para o desenvolvimento cognitivo dos sujeitos".

Os enunciadores, ou pontos de vista, podem ser mais bem visualizados no esquema polifônico que segue:

E1: Com base na teoria sócio-histórica temos que o desenvolvimento cognitivo dos sujeitos se dá a partir das suas atividades inter-relacionais em seus grupos de convívio

E2: A interação é suficiente para o desenvolvimento cognitivo dos sujeitos.

E3: Contudo, a simples interação não é suficiente para que o sujeito se aproprie de novas habilidades cognitivas.

E4: Apenas a interação não é suficiente para o desenvolvimento cognitivo dos sujeitos.

Assim sendo, diante da distribuição entre os vários pontos de vista postos em cena pelo locutor, é pertinente assinalar que o locutor se posiciona da seguinte forma: identifica-se com E3 e E4, pontos de vista assumidos pelo locutor do texto, aprova E1, por mostrar-se de acordo com esse enunciador, e rechaça parcialmente E2.

O rechaço parcial em relação ao enunciador E2 se dá pelo fato de o locutor perceber que o motivo de a interação não ser vista como a responsável total pelo desenvolvimento cognitivo dos sujeitos não significa dizer que ela não possa, de alguma forma que seja, ter um pouco de responsabilidade nesse desenvolvimento cognitivo. 
EID\&A - Revista Eletrônica de Estudos Integrados em Discurso e Argumentação, Ilhéus, n. 14, jul/dez.2017.

Nesse caso, tal compreensão é justificada pela presença da expressão "não é suficiente", que faz com que o leitor entenda que ainda que apenas a interação não seja suficiente, há uma ajuda. Pode-se dizer que há aí uma avaliação por parte do locutor do texto diante do conteúdo apresentado e a partir da qual o locutor se posiciona em relação aos demais pontos de vista apresentados, justificando seu posicionamento, ao negar o caráter de completude presente em E2. Assim, a interação por si só não é totalmente suficiente, uma vez que é necessária a presença de outros elementos para que o desenvolvimento cognitivo dos sujeitos se dê de forma completa.

Logo, o locutor rechaça parcialmente esse enunciador, pois considera a interação como um elemento participante nesse desenvolvimento. Essa noção é ainda trazida à tona com a continuidade (parte final do resumo) do texto, quando o locutor afirma que "interações com alta taxa de positividade nem sempre resultam numa construção coletiva de conhecimento". Isto é, em ambientes virtuais, também, é preciso um elemento a mais do que apenas a interação.

Resumo 04:

As pessoas surdas são sujeitos especialmente visuais no modo de apreensão do mundo. Os estudos linguísticos nas línguas de sinais trouxeram uma nova perspectiva para as ciências relacionadas à surdez. Os estudos sobre escrita e sujeitos surdos ainda se mostram insipientes na produção científica fonoaudiológica. A partir da prática com surdos e de observações empíricas do ensino do português escrito, acredita-se na importância de os sentidos serem partilhados para que a aquisição da linguagem escrita seja efetivada, a partir dos princípios da uma segunda língua (L2). Portanto, este trabalho tem como objetivo investigar a produção escrita de aprendizes surdos e sua relação com a Língua Brasileira de Sinais. Para tanto, foi composta uma equipe com três professoras do Departamento de Fonoaudiologia da UFPE, dez graduandas e uma intérprete de Libras. A metodologia consta em encontros semanais para: (a) avaliação dos perfis dos surdos; (b) estudos à luz de referenciais teóricos sobre surdez (SKLIAR, 1997, 2008; STROBEL, 2008; QUADROS, 2004), gêneros textuais (BAKHTIN, 1995) e ensino de português como L2 (DIDONATO, 2008; GRANNIER 2005; BROCHADO, 2003, 2007); (c) propostas das intervenções; (d) e acompanhamento dos discentes. A amostra foi constituída por seis surdos atendidos duas vezes por semana na clínica-escola de Fonoaudiologia da UFPE. Este estudo encontra-se em andamento, todavia, já apontam significativas conquistas dos surdos na apropriação da escrita do português.

É pertinente apontar, no resumo de número 04, que a existência dos quatro enunciadores se mostra a partir do seguinte esquema polifônico:

E1: Este estudo encontra-se em andamento

E2: não há resultados 
EID\&A - Revista Eletrônica de Estudos Integrados em Discurso e Argumentação, Ilhéus, n. 14, jul/dez.2017.

E3: todavia, já apontam significativas conquistas dos surdos na apropriação da escrita do português

E4: já há resultados

Um olhar mais acurado sobre os quatro enunciadores nos permite dizer que E1 conduz à conclusão E2, que, por sua vez, será totalmente oposta àquela elaborada com base na leitura de $E_{3}$, ou seja, à conclusão E4. O efeito de sentido produzido por "todavia”, que inicia a proposição presente em E3, tem papel fundamental de rechaço total, uma vez que por meio dela há uma quebra integral do que havia sido pensado, inicialmente, apenas com base na conclusão de E1. Logo, teremos E2 e E4 como conclusões opostas, função primeira do operador de contraposição.

O comportamento do locutor diante dos enunciadores presentes é: aprova E1, identifica-se com E3 e E4 e rechaça E2. Ainda que não seja objetivo nosso aqui, não podemos deixar de destacar a presença maciça de nomes de autores (argumentação por autoridade) que o autor do resumo faz uso com o objetivo de dar mais relevância ao seu texto. Entendemos que ao trazer para a apresentação do que será a sua pesquisa nomes como "STROBEL (2008), QUADROS (2004), BAKHTIN (1995), DIDONATO (2008) e GRANNIER (2005)”, o locutor deixa claro o lugar linguístico de onde fala e tem, com isso, a intenção de persuadir a banca parecerista quanto à aceitação do seu texto.

Resumo 05:

Nas gramáticas e nos manuais tradicionais de Língua Portuguesa, geralmente de orientação mais estruturalista, as orações adjetivas são apresentadas como componentes do estudo da "subordinação", ao lado das chamadas "orações substantivas" e "orações adverbiais". Nessas obras, o que se pode evidenciar é que o principal objetivo das explicações apresentadas é o de levar o leitor a diferenciar entre as adjetivas do tipo 'restritiva' e as do tipo 'explicativa'. Outro conjunto de trabalhos integrantes da literatura linguística focaliza as funções sintáticas (seus valores como adjuntos adnominais ou como apostos) e/ou semânticas (seu papel de diminuir, ou não, a extensão do termo a que se refere e, assim, aumentar sua compreensão) das orações adjetivas. No entanto, são escassos os trabalhos acerca das funções textuais e/ou discursivas dessas orações e dos seus subtipos. Com o intuito de colaborar para diminuir essa lacuna, este trabalho objetiva apresentar e discutir o funcionamento textual e discursivo das orações adjetivas, inseridas em contextos reais de uso. Adotando como referencial teórico as propostas de autores funcionalistas (especialmente HALLIDAY, 1985; NEVES, 1999; 2000), a análise aqui empreendida tomou como objeto de pesquisa dados coletados de textos escritos, de graus variáveis de formalidade, dos seguintes gêneros da língua portuguesa: da esfera acadêmica (teses, dissertações, ensaios e artigos científicos), da esfera jornalística (notícias, anúncios e editoriais) e da esfera literária (crônicas, contos e fábulas). 
EID\&A - Revista Eletrônica de Estudos Integrados em Discurso e Argumentação, Ilhéus, n. 14, jul/dez.2017.

O operador "no entanto", utilizado no resumo 05, opõe conclusões que são elaboradas a partir de porções textuais bem maiores, e não apenas de enunciados. É pertinente pontuar, conforme já ocorreu nos textos anteriormente analisados, que, aqui, também há a presença dos quatro enunciadores.

O primeiro argumento apresentado, que compreende a sequência "Outro conjunto de trabalhos integrantes da literatura linguística [...] das orações adjetivas" permite ao interlocutor elaborar a conclusão de que "há trabalhos que abordam a questão do funcionamento das orações adjetivas".

Com a utilização do operador "no entanto" que une as duas porções textuais e introduz novo argumento, o de que "são escassos os trabalhos acerca das funções textuais e/ou discursivas dessas orações e dos seus subtipos", o interlocutor vê-se na condição de elaborar uma conclusão que será oposta àquela elaborada tão somente com base no argumento anteriormente apresentado. Nesse caso, ele irá concluir que "os trabalhos existentes não abordam a questão da descrição do funcionamento das orações adjetivas", isto é, conclusões que são totalmente opostas.

A partir da explicitação dos enunciadores apresentados pelo locutor do texto, é pertinente pensar no seguinte desenho polifônico para tais pontos de vista:

E1: [...] Outro conjunto de trabalhos integrantes da literatura linguística focaliza as funções sintáticas (seus valores como adjuntos adnominais ou como apostos) e/ou semânticas (seu papel de diminuir, ou não, a extensão do termo a que se refere e, assim, aumentar sua compreensão) das orações adjetivas.

E2: há trabalhos existentes que abordam a questão da descrição do funcionamento das orações adjetivas

E3: No entanto, são escassos os trabalhos acerca das funções textuais e/ou discursivas dessas orações e dos seus subtipos.

E4: os trabalhos existentes não abordam a questão da descrição do funcionamento das orações adjetivas.

Consequentemente, diante dos quatro pontos de vista postos em cena pelo locutor do texto, este último irá se posicionar da seguinte forma: rechaça totalmente E2, aprova E1, identifica-se com E3 e E4.

Assim como no resumo anterior, o autor faz uso de argumentação por autoridade, ao trazer para o seu texto nomes que situam sua pesquisa e, com isso, justificar não apenas a importância do seu texto, mas o fato de que o seu 
EID\&A - Revista Eletrônica de Estudos Integrados em Discurso e Argumentação, Ilhéus, n. 14, jul/dez.2017.

trabalho irá se desenvolver em uma vertente que perceberá o funcionamento das orações adjetivas.

Logo, a pesquisa proposta pelo locutor do texto irá caminhar por uma linha de pensamento que privilegia E3 e E4. Essa observação é possível de ser feita pela presença dos autores, aportes teóricos, trazidos pelo locutor do texto, quando esses se propõem a fazer uma análise do funcionamento de estruturas da língua (e da própria língua) bem como pelo fato da inexistência de pesquisas nessa área, ponto de vista apontado pelo locutor em E4. Assim, o operador "no entanto" possibilita um efeito de sentido argumentativo que será construído ao longo de todo o texto, pelo autor do resumo.

\section{Considerações finais}

Conforme é possível perceber, a partir das análises aqui realizadas a respeito do funcionamento linguístico-discursivo dos operadores de contraposição nos cinco resumos apresentados, esses elementos demonstraram que o seu uso foge do que é proposto pelo pensamento tradicionalista, quando os tratam como simples palavras que servem para ligar palavras e orações.

Assim, vimos que a função dessas estruturas vai além de simplesmente ligar termos sintaticamente equivalentes, tendo em vista que, de acordo com nossas análises, os operadores, no gênero resumo acadêmico, são responsáveis por um efeito de sentido que ativam pontos de vista diferentes e possibilitam ao leitor perceber o posicionamento do locutor responsável pelo texto, em relação aos vários pontos de vista postos em cena.

Os resultados mostraram, ainda, que apesar de os resumos serem espécies de comunicações com um padrão rígido de normatização, e que estabelecem relações interpessoais formais, há, também nesses textos, espaço para subjetividade, para a intenção do locutor em produzir uma reação no seu suposto interlocutor, por meio de elementos linguístico-discursivos, o que amplia a discussão sobre a neutralidade, impessoalidade e imparcialidade de determinados textos predefinidos como "objetivos".

Com os resultados alcançados, podemos perceber que o funcionamento semântico argumentativo desses elementos no gênero resumo acadêmico se constitui como uma das principais estratégias argumentativas. Além disso, embora questões como a objetividade e a impessoalidade estejam presentes 
EID\&A - Revista Eletrônica de Estudos Integrados em Discurso e Argumentação, llhéus, n. 14, jul/dez.2017.

nas orientações da produção de textos dessa natureza, tais questões refletem, tão somente, uma pretensa objetividade, visto que o uso que fazemos da língua/gem é, por natureza, subjetivo.

Pesquisas nessa perspectiva são sempre importantes para os estudos linguísticos, não apenas por tentar descrever e analisar elementos utilizados pelos indivíduos de uma sociedade cotidianamente, mas por possibilitar um novo olhar para antigos conceitos e classificações.

\section{Referências}

ANSCOMBRE, Jean-Claude; DUCROT, Oswald. La argumentación en la lengua. Versión española de Julia Sevilha e Marta Tordesillas. Madrid: Editora Gredos, 1994.

. L'argumentation dans la langue. Mardaga : Bruxelas, 1983.

BAKHTIN, Mikhail. Problemas da Poética de Dostoievsky. Trad. Paulo Bezerra. 3 ed. Rio de Janeiro: Editora Forense-Universitária, 1981.

DUCROT, Oswald. O dizer e o dito. Rev. trad. Eduardo Guimarães. Campinas, SP, Pontes, 1987.

- Polifonia e argumentação: Conferencía del Seminário Teoria de la Argumentación y Analisis del Discurso. Cali, Universidad del Valle, 1988.

KOCH, Ingedore G. Villaça. A coesão textual. 7 ed. São Paulo: Contexto, 1999.

. Argumentação e linguagem. 8 ed. São Paulo: Cortez, 2004.

Forma de citação sugerida:

SILVA, Marcos Antônio da; ANDRADE, Luiz Henrique Santos de. A construção da argumentação no resumo acadêmico a partir da utilização dos operadores de contraposição. EID\&A - Revista Eletrônica de Estudos Integrados em Discurso e Argumentação, llhéus, n. 14, p. 83-100, jul/dez.2017.

Recebido em: 29/07/2017

Aprovado em: 16/10/2017 